\title{
EVALUATION OF FAMOTIDINE LOADED 3D-NANO-CELLULOSE NETWORK USED FOR ORAL ADMINISTRATION
}

\author{
VAN-HUNG MAI ${ }^{1}$, XUAN-THANH NGUYEN ${ }^{2}$, THI-KIM-HUE PHUNG ${ }^{3}$, THI-PHUONG L. E. ${ }^{4 *}$
}

${ }^{1}$ Research Center for Anthropology an Mind Development, VNU University of Education, Vietnam, ${ }^{2}$ Institute of Scientific Research and Applications, Hanoi Pedagogical University 2, Vietnam, ${ }^{3}$ Institute of Health Research and Educational Development in Central Highlands, Vietnam, ${ }^{4 *}$ Department of Education, VNU University of Education, Vietnam Email: lethiphuong@vnu.edu.vn

Received: 27 Apr 2020, Revised and Accepted: 30 Jun 2020

\section{ABSTRACT}

Objective: Evaluation Of Famotidine Loaded 3D-Nano-Cellulose Network three dimensional nano-cellulose network (3DNC) Used For Oral Administration. 3DNC is produced from bacteria living in fermented green tea and is the material containing nano-sized fibers, which is capable of loading Famotidine to form a prolonged release therapy to improve drug bioavailability.

Methods: Used healthy white rabbits, weight approximately $2.5-2.7 \mathrm{~kg}$, the same age, laboratory standard, is supplied from The National Institute of Drug Quality Control. The rabbits have adapted to laboratory conditions at least one week and have starveling in $12 \mathrm{~h}$, supplied fully water during the preparation. Rabbits are divided into 4 groups $(\mathrm{n}=3$ for each group). Every rabbit is given 1 capsule or 1 tablet with a single dose of 20 $\mathrm{mg} / \mathrm{rabbit}$ group 1 (commercial drugs), group 2 (3DNC-standard medium (SM) loaded drug), group 3 (3DNC-coconut medium (CM) loaded drug) Group 4 (3DNC-rice medium (RM) loaded drug).

Results: The results have shown that 3DNC has the involvement of the nano-sized cellulose fibers with three-dimensional networks that are capable of loading Famotidine and prolonged drug release. The 3DNC cultured in the drug-loaded SM with slow-release and slow-release catalysts, the 3DNC was cultured in CMs and tablets with medium release rates, in comparison with the 3DNC was cultured in RM loaded at a rapid release rate in the same $\mathrm{pH}=2$.

Conclusion: Experiment on rabbits showed that the drug-loaded 3DNCs could help to prolong the drug release, in which the extended-release time of the 3DNC cultured in SM and CM was higher than that of the 3DNC grown in RM. The 3DNC loaded drugs help improve Famotidine bioavailability compared to commercial tablets.

Keywords: Famotidine, Prolonged-release, Oral delivery

(C) 2020 The Authors. Published by Innovare Academic Sciences Pvt Ltd. This is an open access article under the CC BY license (http://creativecommons.org/licenses/by/4.0/) DOI: http://dx.doi.org/10.22159/ijap.2020v12i5.38061. Journal homepage: https://innovareacademics.in/journals/index.php/ijap

\section{INTRODUCTION}

The 3DNC has the structure of super-thin nanofibers, great tensile, mechanical strength, and so on. Some studies have proved that the 3DNC has the potential of being a delivery system with its properties. Amin M. C. I. M et al. [1] have indicated that the 3DNC membranes can increase the releasing time of the drug and improve the efficiency of drug use. Huang L. et al. [2] have controlled the drug-releasing of the 3DNC in artificial models, including the stomach and intestine. The gained information has shown that Berberine released with a low rate in acidic condition, normal in alkaline condition and high releasing rate in neutral $\mathrm{pH}$ condition. Satishbabu B. K. et al. [3] have assessed slowly releasing drug rate of Famotidine on the cod liver oil combined with calcium alginate granules. Anraku M. et al. [4] have studied the slow release of Famotidine from tablets: chitosan/sulfobutyl ether $\beta$-cyclodextrin composites. Zhu X. et al. [5] have studied the drug delivery system that increased the bioavailability of Famotidine in rats. Maday F. M. et al. [6] have evaluated the acid function of carboxymethyl-betacyclodextrin in improving the chemical stability, oral-route bioavailability, and bitter taste of Famotidine. Fahmy R. H. et al. [7] have tested the rate of release of Famotidine through the construction of liquisolid tablets in both in vitro and in vivo. Gao S. et al. [8] have studied the pharmacokinetics and bioavailability of Famotidine on 10 Chinese volunteers. The objective of study is the evaluation Of Famotidine Loaded 3D-Nano-Cellulose Network three dimensional nano-cellulose network (3DNC) used for oral administration.

\section{MATERIALS AND METHODS}

Materials and chemicals: Famotidine $99.5 \%$ (Sigma-The USA); tablets Famotidine (FAMSYN-20, Haryana-India); Dialysis bag (MWCO: 12000-14000; Serva-Germany); Yeast extract (USA); Peptone (European Union); Methanol, Acetonitrile, Sodium Acetate
Trihydrate, Triethylamine, Ice Acetic Acid,... (Merck); other standard chemicals used in chromatography and analysis.

Laboratory Animal: healthy white rabbits, weight approximately 2.5$2.7 \mathrm{~kg}$, the same age, laboratory standard, is supplied from The National Institute of Drug Quality Control. The rabbits have adapted to laboratory conditions at least one week and have starveling in 12 $\mathrm{h}$, supplied fully water during the preparation. Experiments on rabbits have been approved by the ethical committee for conduction the study, approval number: 458/Ministry of Health of Vietnam.

Determine the physicochemical properties of 3DNC loaded famotidine

The material structure 3DNC loaded drug by scanning electron microscope (SEM), in which the sample heat in $40{ }^{\circ} \mathrm{C}$ is in $20 \mathrm{~min}$. The next step is to cover a thin platinum layer and then put it into the sample chamber.

Use the electron microscope FE-SEM Hitachi S-4800 with magnification $\mathrm{M}=20-800,000 \times$, resolution $\delta=1.0 \mathrm{NM}$ and piezoelectric accelerator $\mathrm{U}=10 \mathrm{kV}$.

Determine the interaction of 3DNC with the drug by the photo spectrometer Fourier transformation infrared (FT-IR): Samples are directly measured by reflectometry in $20^{\circ} \mathrm{C}$, moisture $40-43 \%$.

\section{Research the drug release from 3DNC loaded drug in vitro}

Drug dose, which was released through the delivery system was tested in buffer solution $\mathrm{pH}=2 ; 4.5 ; 6.8$ [9]. According to the Pharmacopoeia of Vietnam [10]. Put 3DNC loaded drug in the dialysis bag, which is dipped in a buffer solution with specific $\mathrm{pH}(2 ; 4.5 ; 6.8)[10]$ during the night with a closed side, then add $5 \mathrm{ml}$ buffer solution with $\mathrm{pH}$ levels respectively. Use Magnetic Stirrer, stirring speed 50 cycles/min, the temperature in range $37^{\circ} \mathrm{C} \pm 0.5^{\circ} \mathrm{C}$. After $0.5 \mathrm{~h} ; 1 \mathrm{~h} ; 1.5$; $2 \mathrm{~h} ; 4 \mathrm{~h} ; 6 \mathrm{~h} ; 8 \mathrm{~h}$; 
$12 \mathrm{~h}$ and $24 \mathrm{~h}$, take samples out to measure the spectral density of the samples. The samples were removed at every $5 \mathrm{ml}$ intervals and adding again $5 \mathrm{ml}$ of a buffer solution. The experiments were repeated three times for the mean value. The ratio of drug release is calculated according to the formula:

$$
\mathrm{R} \%=\frac{C_{\mathrm{t}} x V_{1}+\sum_{\mathrm{i}=1}^{\mathrm{i}=1-1} C_{\mathrm{i}} x V_{2}}{m} \times 100
$$

Where: $\mathrm{R}$ is the drug release ratio; $\mathrm{C}_{t}$ is the concentration of the solution at time $\mathrm{t}$; $\mathrm{V} 1$ is the volume of buffer solution at different $\mathrm{pH}$ values; $\mathrm{n}$ are the number of samples taken from the solution of liberation; V2 is the volume of buffer added; $m$ is the amount of drug absorbed into the 3DNC.

\section{Research the bioavailability of 3DNC loaded drug in vivo}

Testing requirement: 12 laboratory rabbits divided into 4 groups $(n=3$ for each group). Every rabbit has given 1 capsule or 1 tablet with a single dose of $20 \mathrm{mg} / \mathrm{rabbit}$ : group 1 (commercial drugs), group 2 (3DNC-SM loaded drug), group 3 (3DNC-CM loaded drug) Group 4 (3DNC-RM loaded drug).

Sampling method: After the rabbits take the drugs, use blood samples taken from those rabbits before giving the drug (white drug without any medicine), then take blood in turn at $0.5 \mathrm{~h}, 1 \mathrm{~h}, 2 \mathrm{~h}, 4 \mathrm{~h}, 6 \mathrm{~h}, 8 \mathrm{~h}, 10 \mathrm{~h}, 12 \mathrm{~h}$, and $24 \mathrm{~h}$ after drug use [9]. Select suitable veins, the blood is collected behind the ear. Using a sterilized needle to aspirate the vein behind rabbit ears, blood in the test the tube contains anti-coagulants (EDTA). Only after taking the blood samples, was it gently inversed repeatedly to ensure well mixing with anticoagulants and immediately centrifuged at $5000 \mathrm{rpm}$ for $10 \mathrm{~min}$ at $4{ }^{\circ} \mathrm{C}$ to separate the plasma. Floating plasma will be transferred to a clean tube and start to analyze [9].

Quantify $\mathrm{Fa}$ in blood plasma by high-performance liquid chromatography (HPLC) method: Survey the chromatography condition, sampling process and evaluate the analytic technique based on our previous results.

\section{Assessing parameters bioavailability in vivo}

Maximum concentration $\left(\mathrm{C}_{\max }\right)$ : Maximum concentration exposes the intensity of interaction of drugs. The more absorbed the drug is, the faster it reaches the maximum concentration. These concentrations must be higher than the minimum concentration to exhibit clinical responses. However, if the maximum concentration overtakes the safety threshold, the drug will be able to cause unwanted sides [11].

To evaluate bioavailability (BIOA), we use relative BIOA (formula 2.4) when the control products is an oral medication.

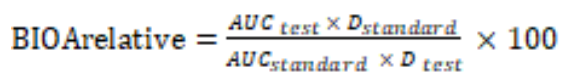

Where: $\mathrm{AUC}_{\text {test }}$ is the curve area of testing drug; $\mathrm{AUC}_{\text {standard }}$ is curve area of control drug; $D_{\text {test }}$ is the testing dose of the testing drug; $\mathrm{D}_{\text {standard }}$ is the testing dose of control drug.

If the testing products have $\mathrm{BIOA}=80-125 \%$ compared to the control products, it will be considered that is biological equivalence with the control products [11]. All results are analyzed, processed by Excel 2010, and the pharmacokinetic parameters were calculated, processed by PK Solver software [12].

\section{RESULTS AND DISCUSSION}

\section{Evaluate the release capacity of famotidine from 3DNC loaded drug in vitro}

Conduct drug release in vitro from the 3DNC loaded materials under environmental conditions $\mathrm{pH}=2 ; 4.5$ and 6.8. The results of the drug release rate for the 3DNC types cultured in SM, CM, and RM loaded in the different $\mathrm{pH}$ media are shown in fig. 1 . The results indicated that the 3DNC cultured in SM loaded drug after $12 \mathrm{~h}$ had a higher drug release rate at $\mathrm{pH}=2(88.79 \%)$ and $\mathrm{pH}=4.5(86.47 \%)$, lower than at $\mathrm{pH}=6.8(74.36 \%)$. At $\mathrm{pH}=2$ and $\mathrm{pH}=4.5$; the drug release rates from the 3DNC were cultured in SM slower but has a higher rate at $\mathrm{pH}=6.8$. After $12 \mathrm{~h}$, the drug release rate from the 3DNC in CM loaded drug has a high release rate of the Faat $\mathrm{pH}=2(88.11 \%)$ and at $\mathrm{pH}=4.5(89.99 \%)$, lower than $\mathrm{pH}=6.8(78.94 \%)$. The 3DNC cultured in $\mathrm{CM}$ loaded drug has been released at a faster rate at $\mathrm{pH}=$ 6.8 and releases less than the remaining $\mathrm{pH}$. Just after $6 \mathrm{~h}$, the 3DNC was cultured in RM loaded with the high acid release rate at $\mathrm{pH}=2$ $(92.52 \%)$ and $\mathrm{pH}=4.5(93.19 \%)$, lower than at $\mathrm{pH}=6.8(83.69 \%)$. In the investigated $\mathrm{pH}$, the 3DNC was cultured in $\mathrm{RM}$ loaded $\mathrm{Fa}$ having a fast and high rate of drug release.

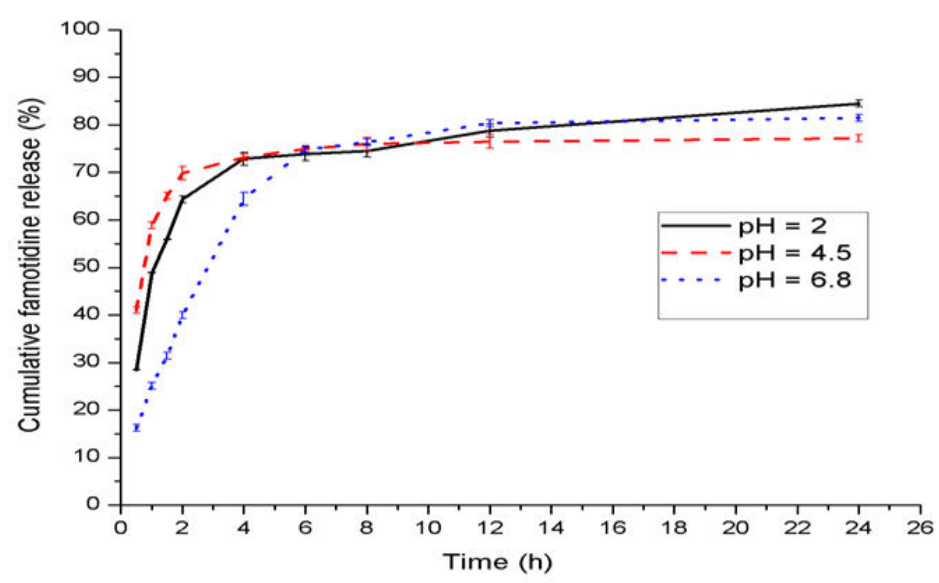

a) 3DNC produced from SM loaded drug $(\mathrm{n}=3)$, $\mathrm{n}$ : number of experiments; mean $\pm \mathrm{SD}$ : $\mathrm{pH}=2(62.1 \pm 0.29)$; $\mathrm{pH}=4.5(61.3 \pm 0.18)$; $\mathrm{pH}=6.8$ $(55.2 \pm 0.34)$

The results in fig. 1 stated that just after $6 \mathrm{~h}$, commercial tablets Famotidine had a high rate of Fa release at $\mathrm{pH}=2(84.45 \%)$, lower than $\mathrm{pH}=4.5(78.16 \%)$ and $\mathrm{pH}=6.8(69.00 \%)$. At $\mathrm{pH}=2$, the rate of drug release from commercial tablets Fa was slower but higher than at $\mathrm{pH}=4.5$ and at $\mathrm{pH}=6.8$.

The comparison results of the $\mathrm{pH}$ effect on the drug release capacity of each drug-loaded 3DNC and of the commercial tablets Fa are shown in fig. 1. The results expressed that in highly acidic environments $(\mathrm{pH}=$
2), each drug-loaded 3DNC, as well as the commercial tablets, had a higher $\mathrm{Fa}$ release rate than $\mathrm{pH}=4.5$ and $\mathrm{pH}=6.8$. This evidence may explain that $\mathrm{Fa}$ is well soluble in the acidic environment, so the drug will release better from the drug-loaded 3DNC as well as from the tablets. The result is consistent with other studies $[2,13]$.

The comparative results on the Fa release capacity of three drugloaded 3DNC types and commercial tablets $\mathrm{Fa}$ in the media $\mathrm{pH}=2$; $\mathrm{pH}=4.5$ and $\mathrm{pH}=6.8$ was shown in fig. 2 . 


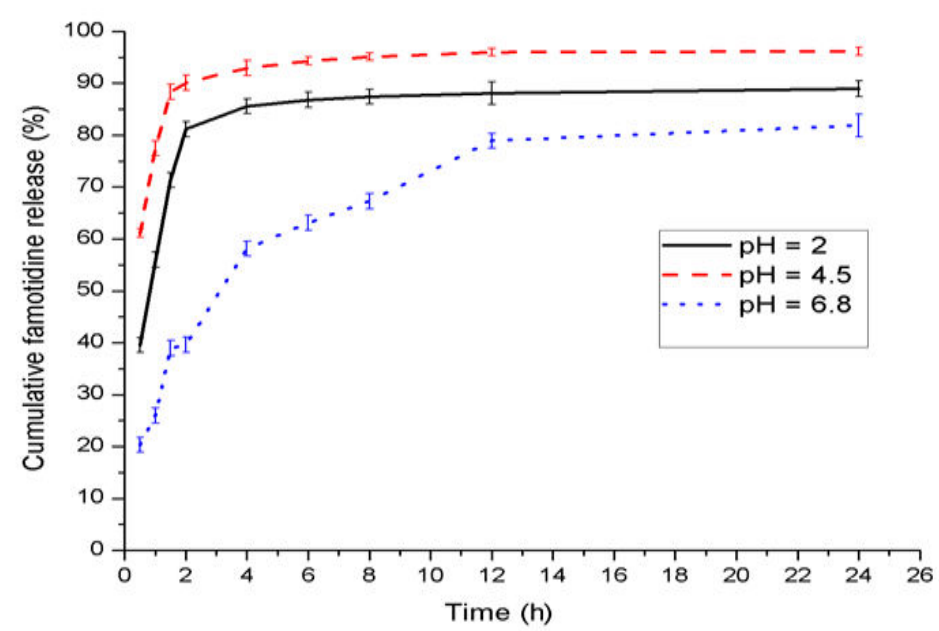

b) 3DNC produced from CM loaded drug $(\mathrm{n}=3)$, $\mathrm{n}$ : number of experiments; mean $\pm \mathrm{SD}$ : $\mathrm{pH}=2$ (68.9 \pm 0.27$) ; \mathrm{pH}=4.5(89.1 \pm 0.84) ; \mathrm{pH}=6.8$ $(57.6 \pm 0.38)$

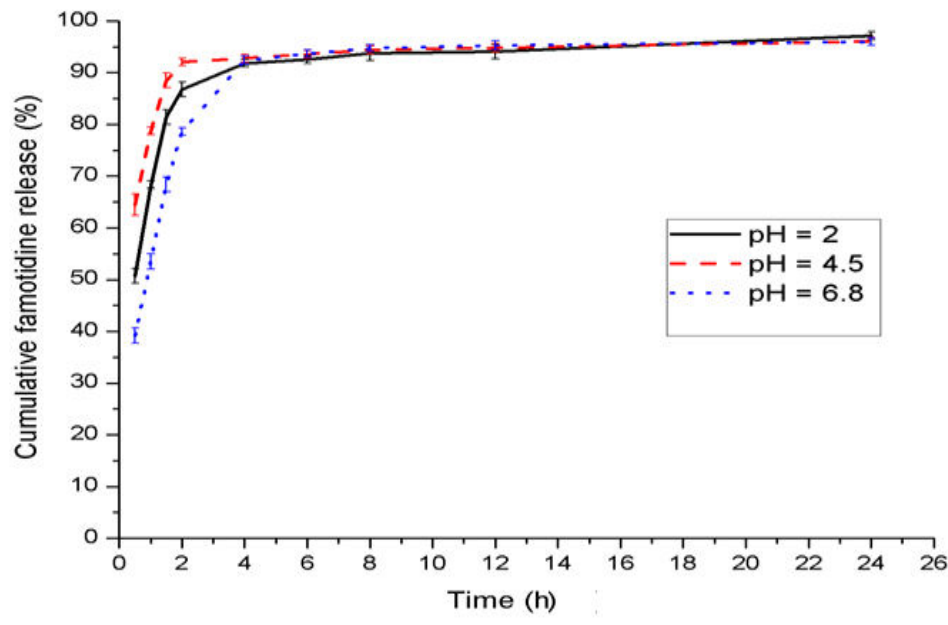

c) $3 \mathrm{DNC}$ produced from $\mathrm{RM}$ loaded drug $(\mathrm{n}=3)$, $\mathrm{n}$ : number of experiments; mean $\pm \mathrm{SD}$ : $\mathrm{pH}=2$ (71.9 \pm 0.25$) ; \mathrm{pH}=4.5(83.5 \pm 0.18) ; \mathrm{pH}=6.8$ (74.1 \pm 0.33$)$

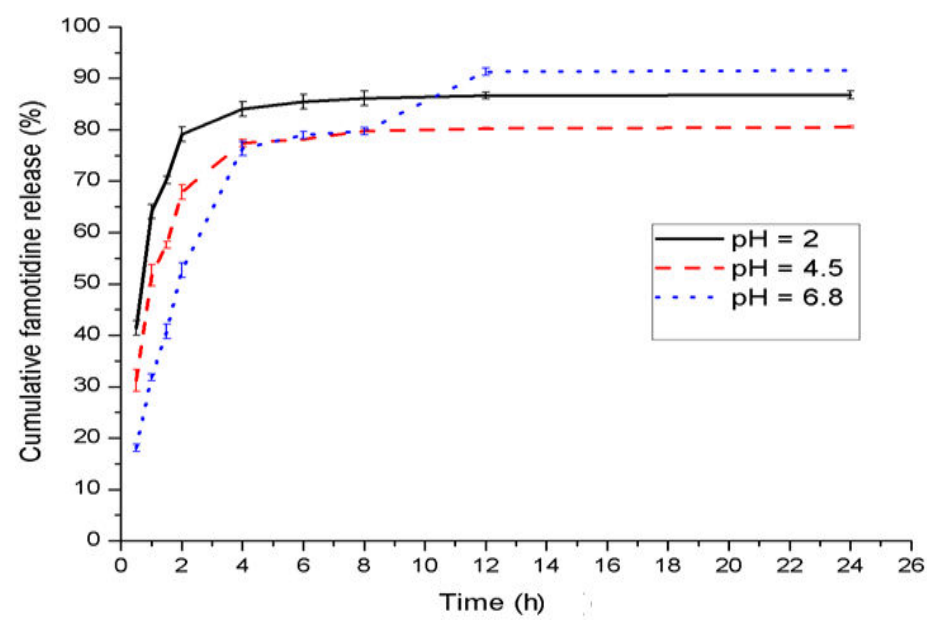

d) Commercial Famotidine tablets $(\mathrm{n}=3)$, $\mathrm{n}$ : number of experiments; mean $\pm \mathrm{SD}$ : $\mathrm{pH}=2(56.4 \pm 0.14) ; \mathrm{pH}=4.5(57.7 \pm 0.17) ; \mathrm{pH}=6.8$ $(62.6 \pm 0.39)$

Fig. 1: Percentage of Famotidine release from the 3DNC produced from SM, CM, and RM loaded drug in the different pH environments 


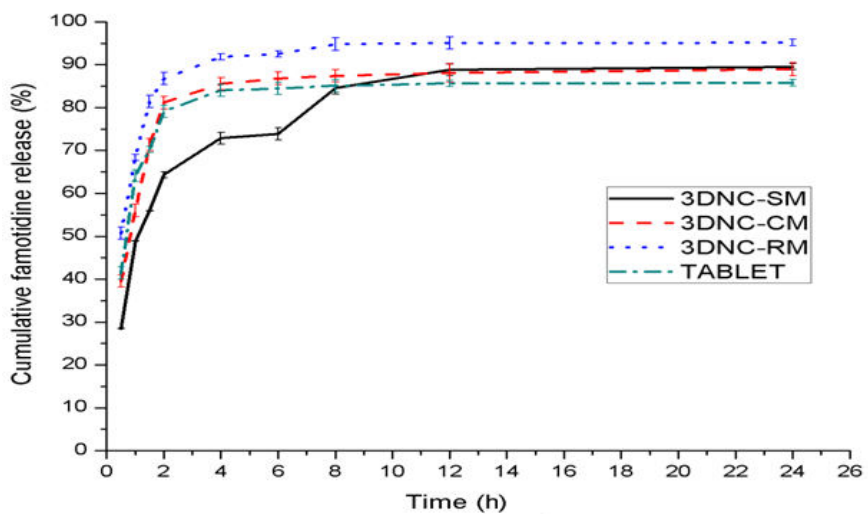

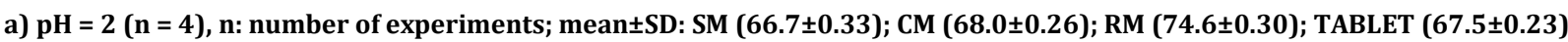

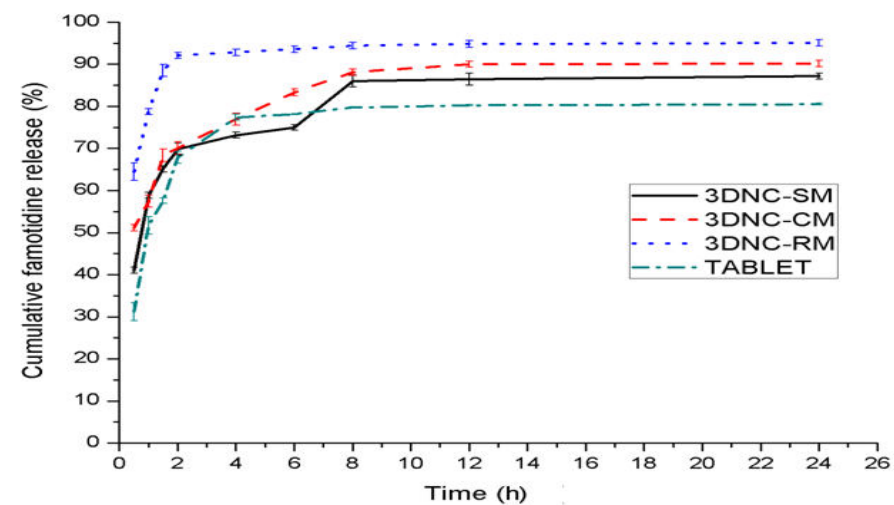

b) $\mathrm{pH}=4.5 ;(\mathrm{n}=4)$, $\mathrm{n}$ : number of experiments; mean \pm SD: SM (70.9 \pm 0.25$) ; \mathrm{CM}(75.6 \pm 0.22) ; \mathrm{RM}(83.1 \pm 0.18) ;$ TABLET (61.6 \pm 0.28$)$

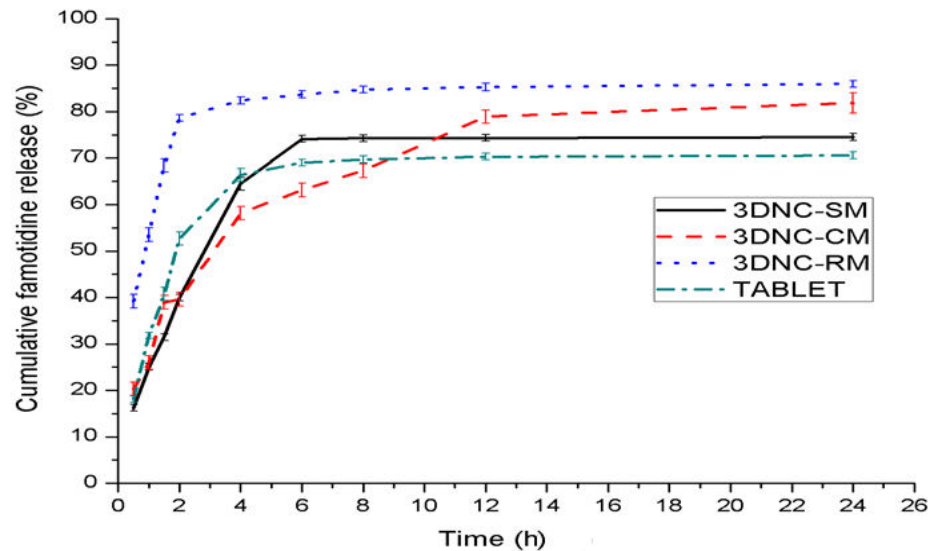

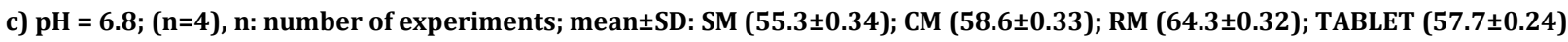

Fig. 2: Percentage of Famotidine released from three 3DNC types loaded drug and commercial tablets Famotidine in distinct pH environments

Research results showed that the 3DNC cultured in the drug-loaded SM with slow-release and slow-release catalysts, the 3DNC was cultured in CMs and tablets with medium release rates, whereas the 3DNC was cultured in RM loaded at a rapid release rate in the same $\mathrm{pH}=2$ medium. This can be explained by the SEM image showing that the size of the hole in the membrane is larger and that the number of holes is greater than the other ones, thus releasing the drug to the environment faster. This result is consistent with other studies [2].

Hence, in high acidic environments $(\mathrm{pH}=2)$, each drug-loaded $3 \mathrm{DNC}$, as well as the commercial tablets, had higher the $\mathrm{pH}$ release rates than at $\mathrm{pH}=4.5$ and $\mathrm{pH}=6.8$. The 3DNC cultured in drugloaded SM has a slow and prolonged release, the 3DNC cultured in the drug-loaded CM and tablets have medium release rates, whereas the 3DNC cultured in the drug-loaded RM has a fast release in the same $\mathrm{pH}$ environment.

Evaluate bioavailability in vivo of famotidine release from 3DNC

The analytic progress of Fa in the rabbit plasma was built, including sampling processes and analytical methods by HPLC. Throughout the survey, methanol solvent samples were selected, highperformance liquid chromatography conditions suitable for 
columns, mobile phases, detectors, flow rates, injection volumes allowed for $\mathrm{Fa}$ analysis in rabbit plasma with a small detective limit of $0.0644 \mu \mathrm{g} / \mathrm{ml}$ and a quantity limit of $0.212 \mu \mathrm{g} / \mathrm{ml}$ [14]. The Fa quantitative procedure in rabbit plasma has been evaluated for specificity, linearity, defined range, definite limit, quantitative limit, correctness, accuracy, precision. The results of the study show that the method is suitable for estimating Fa in rabbit plasma [14]. The rabbit plasma samples obtained after oral administration of three doses of the drug-loaded 3DNC and Fa tablets with the same concentration of $20 \mathrm{mg} / \mathrm{rabbit}$ [15] were processed and quantified according to the method described in our previous study [14]. The results of the Fa determination of rabbit plasma concentration after drinking the three types of 3DNC loaded drugs and the Fa tablets are shown in table 1 .

Table 1: Famotidine concentration in rabbit plasma after administering three types of the drug-loaded 3DNC and Famotidine tablets with the same concentration $20 \mathrm{mg} / \mathrm{rabbit}(\mathrm{n}=3)$

\begin{tabular}{|c|c|c|c|c|}
\hline Time (h) & $\begin{array}{l}\text { 3DNC-SM }(\mu \mathrm{g} / \mathrm{ml}) \\
\text { mean } \pm \text { SD }\end{array}$ & $\begin{array}{l}\text { 3DNC-CM }(\mu \mathrm{g} / \mathrm{ml}) \\
\text { mean } \pm S D\end{array}$ & $\begin{array}{l}\text { 3DNC-RM }(\mu \mathrm{g} / \mathrm{ml}) \\
\text { mean } \pm \text { SD }\end{array}$ & $\begin{array}{l}\text { Tablet }(\mu \mathrm{g} / \mathrm{ml}) \\
\text { mean } \pm \text { SD }\end{array}$ \\
\hline 0.5 & $2.641 \pm 0.154$ & $5.641 \pm 0.154$ & $6.917 \pm 0.292$ & $6.479 \pm 0.979$ \\
\hline 1 & $6.006 \pm 0.278$ & $8.567 \pm 0.220$ & $9.520 \pm 1.565$ & $11.860 \pm 0.760$ \\
\hline 2 & $9.751 \pm 0.286$ & $9.504 \pm 0.279$ & $11.318 \pm 0.656$ & $14.015 \pm 0.933$ \\
\hline 4 & $10.946 \pm 0.146$ & $10.687 \pm 0.082$ & $12.972 \pm 0.526$ & $9.931 \pm 0.711$ \\
\hline 6 & $11.723 \pm 0.138$ & $11.410 \pm 0.190$ & $11.518 \pm 0.332$ & $7.887 \pm 1.068$ \\
\hline 8 & $11.274 \pm 0.086$ & $10.604 \pm 0.102$ & $6.410 \pm 0.456$ & $4.364 \pm 0.463$ \\
\hline 10 & $8.906 \pm 0.465$ & $8.037 \pm 0.182$ & $3.974 \pm 0.245$ & $2.666 \pm 0.319$ \\
\hline 12 & $5.804 \pm 0.244$ & $4.761 \pm 0.288$ & $2.689 \pm 0.343$ & $0.933 \pm 0.218$ \\
\hline 24 & $0.834 \pm 0.047$ & $0.517 \pm 0.277$ & $0.207 \pm 0.103$ & $0.031 \pm 0.006$ \\
\hline
\end{tabular}

(n: number of experiments)

The results in table 1, indicated that, at the early time of the survey, the rabbit plasma concentrations increased slowly in the rabbits using the 3DNC cultured from SM or the 3DNC cultured from CM but increased rapidly when the rabbits using the 3DNC cultured from drug-loaded RM or commercial tablets Fa. Almost all of the time, the
Fa concentrations in the rabbit plasma using drug-loaded membranes are higher than the rabbits taking commercial tablets.

To better illustrate the differences in plasma concentrations of Fa among four groups of rabbits, the data were expressed as a mean of the curve of Fa concentration following the time (fig. 3).

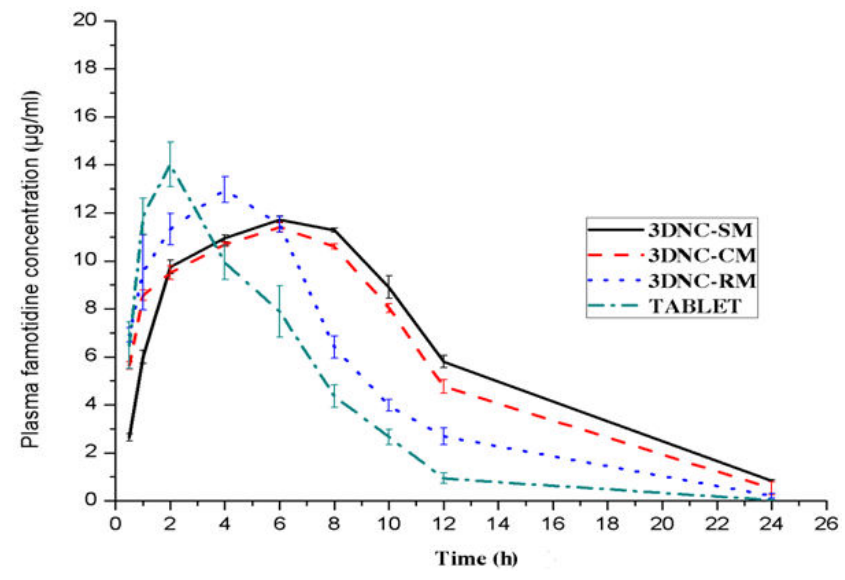

Fig. 3: Expressing famotidine concentrations in rabbit plasma following the time $(n=4), n$ : number of experiments; mean $\pm S D$ : SM

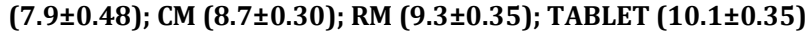

Table 2: Average pharmacokinetic parameters of three 3D-nano-cellulose structural network and commercial tablets famotidine (n= 4)

\begin{tabular}{|c|c|c|c|c|c|}
\hline Parameter & Unit & 3DNC cultured from SM & 3DNC cultured from CM & 3DNC cultured from RM & Tablet \\
\hline $\mathrm{T}_{\max }$ & hour & 6 & 6 & 4 & 2 \\
\hline $\mathrm{C}_{\max }$ & $\mu \mathrm{g} / \mathrm{ml}$ & 11.72 & 11.41 & 12.97 & 14.02 \\
\hline$t_{1 / 2}$ & hour & 4.21 & 3.64 & 3.27 & 2.24 \\
\hline $\mathrm{AUC}_{0-\mathrm{t}}$ & hour. $\mu \mathrm{g} / \mathrm{ml}$ & 152.44 & 142.82 & 119.12 & 91.19 \\
\hline $\mathrm{AUC}_{0-\infty}$ & hour. $\mu \mathrm{g} / \mathrm{ml}$ & 157.51 & 145.53 & 120.09 & 91.29 \\
\hline
\end{tabular}

(n: number of experiments)

The indexes relating to the drug absorption by oral administration on rabbit groups taking the drug-loaded 3DNC types and commercial Fa tablets were shown in table 2 .

The results in table 2, showed that the rabbits using the 3DNC cultured from SM, 3DNC cultured from CM, the 3DNC cultured from the RM loaded drug and commercial tablets Fa obtained $C_{\max }$ after 6 , $6,4,2 \mathrm{~h}$, indicating that $\mathrm{Fa}$ in the commercial tablets is absorbed faster than the loaded $\mathrm{Fa}$ in the 3DNC types. Maximum drug concentrations in the plasma of the rabbits taking the drug-loaded 3DNC were lower than the rabbits taking the commercial Fa tablets. The half-life $\left(t_{1 / 2}\right)$ and the area under the curve (AUC) of drug-loaded 3DNCs were higher than the commercial Fa tablets. $\mathrm{T}_{\max }$ of the 3DNC cultured from SM and CM was higher than the 3DNC cultured from the drug-loaded RM and the commercial Fa tablets were the smallest $\mathrm{T}_{\text {max }}$. Thus, the types of 3DNC loaded drugs can help with the prolonged drug release, in which the extended-release time of 3DNC membrane cultured from SM and the 3DNC was cultured from CM 
loaded higher than the 3DNC cultured from the RM loaded drug. The in vivo bioavailability of drug-loaded 3DNC cultured in the standard media was $172 \%$, the drug-loaded 3DNC in the coconut nutrient culture was $159 \%$, the drug-loaded 3DNC in rice nutrient cultures were $131 \%$ compared to the tablets on the market. The drug-loaded 3DNCs have supports to improve the Fa bioavailability compared to commercial tablets. These results are similar to the study results assessing the Fa bioavailability in some other products [15]

\section{CONCLUSION}

In strong acidic environments $(\mathrm{pH}=2)$, the $3 \mathrm{DNC}$ was cultured in $\mathrm{SM}$ with slow Famotidine release rate and extended-release $(88.79 \%$ release rate) is the most effective one. Experiment on rabbits showed that the drug-loaded 3DNCs could help to prolong the drug release, in which the extended-release time of the 3DNC cultured in SM and CM was higher than that of the 3DNC grown in RM. The 3DNC loaded drugs help improve Famotidine bioavailability compared to the commercial tablets.

\section{ACKNOWLEDGMENT}

The authors are thankful to the members of Biomedical and Pharmaceutical Engineering Research Group (BIPERG) at the Institute of Scientific Research and Applications (ISA)-Hanoi Pedagogical University 2 (HPU2), Research Center for Anthropology and Mind development (CAMD), VNU University of Education and collaborative members who have helped to do some of the work of this research. The authors would like to thank the Institute of Scientific Research and Applications (HPU2) for providing necessary facilities and support.

\section{FUNDING}

Nil

\section{AUTHORS CONTRIBUTIONS}

The first author author conceived the idea. All the authors have carried out the research work under the supervision of the first author. The first author drafted the manuscript.

\section{CONFLICT OF INTERESTS}

The authors declare no conflicts of interest

\section{REFERENCES}

1. Amin MCIM, Ahmad N. Bacterial cellulose film coating as a drug delivery system: physicochemical, thermal, and drug release properties. Sain Malaysiana 2012;41:561-8.
2. Huang L., Chen X, Thanh Xuan Nguyen. Nano-cellulose 3Dnetworks as controlled-release drug carriers. J Mater Chem B 2013;1:2976-84.

3. Satishbabu BK, Shurtinag R, Sandeep VR. Formulation and evaluation of floating drug delivery system of famotidine. Indian J Pharm Sci 2010;6:738-44.

4. Anraku M, Hiraga A, Iohara D, Pipkin JD, Uekama K. Slowrelease of famotidine from tables consisting of chitosan/sulfobutyl ether $\beta$-cyclodextrin composites. Int J Pharm 2015;487:142-7.

5. Zhu X, Zhang Z, Qi X, Xing J. Preparation of multiple-unit floating-bioadhesive cooperative minitablets for improving the oral bioavailability of famotidine in rats. Drug Delivery 2014;6:459-66.

6. Maday FM, Khaled KA, Yamasaki K, Iohara D, Taguchi K, Anraku $\mathrm{M}$, et al. Evaluation of carboxymethyl-beta-cyclodextrin with acid function: improvement of chemical stability, oral bioavailability and bitter taste of famotidine. Int J Pharm 2010;397:1-8.

7. Fahmy RH, Kassem MA. Enhancement of famotidinedissolution rate through liquisolid tablets formulation: in vitro and in vivo evaluation. Eur J Pharm Biopharm 2008;3:993-1003.

8. Gao S, Liu GL, Wang SX, Gao XH. Pharmacokinetics and bioavailability of famotidine in 10 healthy Chinese volunteers. Zhongguo Yao Li Xue Bao 1991;3:195-8.

9. Thanh Xuan Nguyen. Chitosan-coated nanoliposomes for the oral delivery of berberin hydrochloride. J Mater Chem B 2014;2:7149-59.

10. Ministry of Health. Pharmacopoeia Vietnam IV. Hanoi Publisher; 2009.

11. Tran Thị Thu Hang. Clinical Pharmacokinetics, Phuong Dong Publisher; 2009.

12. Zhang Y, Huo M, Zhou J, Xie S. An add-in program for pharmacokinetic and pharmacodynamic data analysis in Microsoft Excel. Comput Methods Programs Biomed 2010;3:306-4.

13. Le Thi Phuong Thao, Le Vinh Bao, Nguyen Thien Hai. Formulation of famotidine $40 \mathrm{mg}$ tablet. J Med Sci 2014;2:72-7.

14. Phan Thi Huyen Vy, Bui Minh Thy, Phung Thi Kim Hue, Nguyen Xuan Thanh, Trieu Nguyen Trung. Method validation for famotidine quantitative analysis in rabbit plasma. J Prac Med 2018;1066:46-50.

15. Mishra V. Formulation and pharmacokinetic study of famotidine loaded floating microballoons. Int J Pharm Pharm Sci 2012;4:511-5. 